\title{
Lugares de Fala do leitor no Diário Gaúcho ${ }^{1}$
}

\author{
Márcia Franz Amaral² \\ Universidade Federal de Santa Maria \\ marciafamaral@uol.com.br
}

\begin{abstract}
Resumo: $O$ artigo tem como tema o segmento popular da grande imprensa, mais especificamente os Lugares de Fala dos leitores no jornal Diário Gaúcho (DG). O DG, editado pela Rede Brasil Sul de Comunicação no Rio Grande do Sul, é lido por mais de um milhão de leitores das classes $B, C$ e D. Dedica-se à prestação de serviço, ao entretenimento e à concessão de ampla visibilidade aos seus leitores populares. No caso do DG, a fala dos leitores populares faz a diferença. $O$ trabalho analisa o lugar que a fala do leitor assume no jornal e aborda o jornalismo de referência e o jornalismo popular, para compreender quem é autorizado a falar em cada um deles.
\end{abstract}

Résumé: Cet article a comme thème le segment populaire de la grande presse, plus spécifiquement les Lieus de Parole des lecteurs au journal Diário Gaúcho (DG). Le DG, edité par la Rede Brasil Sul de Comunicação à l'état du Rio Grande do Sul, est lu par plus d'un million de lecteurs clasifiés selon leurs conditions financières comme $B, C$ et $D$. Il s'occupe à la prestation de service, à l'amusement et à la concession d'une vaste visibilité aux lecteurs populairs. Dans le cas du DG, la parole des lecteurs populairs fait la différance. La recherche analyse le lieu que la parole du lecteur prend dans le journal et aborde le journalisme de reférence et le journalisme populair, à fin de comprendre qui est autorisé à parler en chaqu'un d'eux.

Summary: This article has as theme the popular segment of the big press, specifically the readers' Places of Speech on the Diário Gaúcho (DG) newspaper. The DG, edited by Rede Brasil Sul de Comunicação in Rio Grande do Sul, is read by more than a million readers from $C, D$ and $E$ classes. It dedicates itself to the service rendering, entertainment and a wide visibility concession to its popular readers. On DG's case, is the speech of the popular reader that makes the difference. The paper analyses the places that the reader's speech assumes on the newspaper and tackles the reference journalism and the popular journalism to understand who is authorized to speak in each one of them.

Resumen: Este artículo tiene como tema central el segmento popular de la grande prensa, más específicamente los Lugares de Habla de los leedores en el diario Diário Gaúcho (DG). El DG, editado por la Rede

\footnotetext{
${ }^{1} \mathrm{O}$ artigo resume a tese de doutorado apresentada em 2004 ao Programa de Pós-Graduação em Ciências da Informação e da Comunicação.

${ }_{2}^{2}$ Jornalista, professora adjunta da Universidade Federal de Santa Maria.
} 
Brasil Sul de Comunicação en el estado de Rio Grande do Sul, es leído por más de un millón de leedores de categorías $B, C$ y $D$. Dedicase a prestación de servicios, a entretenimiento y a concesión de amplia visibilidad a sus leedores populares. En el caso del DG, el habla de los leedores populares hace la diferencia. El trabajo analiza el lugar a que el habla del leedor asume en el diario y aborda el periodismo de referencia e el periodismo popular, para comprender quien es autorizado a hablar en cada un de ellos.

Palavras-chave: Jornalismo popular, sensacionalismo, matrizes culturais, Lugares de Fala.

Mots-clé: Journalisme populair, sensationalisme, reférence culturelle, lieu de parole.

Key-words: Popular journalism, sensationalism, cultural matrices, speech places.

Palabras clave: Periodismo popular, sensacionalismo, matrices culturales, lugar de habla.

\section{Introdução}

Pesquisamos o segmento popular da grande imprensa, mais especificamente a visibilidade do leitor num jornal gaúcho autodenominado popular. Do ponto de vista da relevância social, é muito produtivo analisar como a imprensa se faz popular. É tarefa do jornalista informar setores mais amplos da população, e, por isso, não é recomendável que fiquemos circunscritos a uma única forma de se fazer jornalismo. Os jornais populares devem ser pesquisados para que seja possível captar suas estratégias e, num movimento crítico, incorporá-las ou descartá-las no sentido de criar bases para um jornalismo popular diferenciado.

O jornalismo não pode prescindir de considerar suas condições antecipadas de recepção e há a necessidade de pensarmos sobre as formas de endereçamento aos setores populares, sob pena de a lógica empresarial encarregar-se totalmente disso. Enquanto as empresas jornalísticas e seus departamentos de marketing desenvolvem cada vez mais técnicas de aproximação do leitor, raros são os trabalhos e pesquisas sobre o jornalismo e suas relações com o público. Se é evidente que o jornalismo não pode se 
submeter inteiramente a lógicas externas, também é crucial que ele se torne mais didático, interessante e vinculado ao universo popular.

$\mathrm{O}$ ato de "conhecer o público" é normalmente remetido ao campo do marketing. A ojeriza à submissão mercadológica tem razões históricas importantes, como as distorções, invenções, exageros e deslizes éticos cometidos em nome do aumento das tiragens. Mas ela não pode fazer com que nós, jornalistas, localizemo-nos no extremo oposto e desenvolvamos um sentimento que apaga do horizonte a existência de um público leitor de jornais.

Se existe uma íntima relação entre a produção e o consumo, é salutar pensarmos o jornalismo no plural, para públicos diferenciados, sem, por isso, termos que abrir mão dos princípios éticos. As mesmas razões éticas que nós, jornalistas, temos para não sujeitar nossa atividade ao mercado de bens materiais, devem levar-nos a refletir mais sobre o mercado simbólico envolvido na atividade jornalística. Afinal, o fato de nos dirigirmos a um determinado tipo de leitor não é uma estratégia só do plano mercadológico, mas, fundamentalmente, do plano comunicacional. Necessitamos nos contrapor a tendências excludentes, pois corremos o risco de termos cada vez mais um jornalismo especializado em atender apenas formadores de opinião e um pseudo-jornalismo dirigido às maiorias.

Hoje, dos doze jornais brasileiros com maior tiragem, seis são orientados para atender um leitor de menor renda. O Diário Gaúcho, tablóide popular editado no Rio Grande do Sul, fica com a sexta colocação nesse ranking. Grandes grupos de comunicação que detêm redes de jornal, rádio e TV têm apostado no segmento popular, como é o caso do Grupo Folha de São Paulo (Agora), do Globo (Extra) e da RBS (DG).

Partimos da insuficiência do conceito de sensacionalismo para analisarmos os novos jornais populares, pois se apresenta inócuo tanto por suas insuficiências, quanto pelas mudanças ocorridas na imprensa auto- 
intitulada popular nos últimos anos. Atualmente, surgem jornais populares que contornam o estilo "espreme que sai sangue". Nossa problemática, passa, então, por outros caminhos: pelo reconhecimento das implicações das posições sociais e simbólicas entre jornal e leitor, pela necessidade da incorporação da noção de mercado de leitores nos estudos sobre o jornalismo, pela análise dos Modos de Endereçamento dessa imprensa e de suas conexões culturais.

Suspeitamos do poder explicativo do conceito de sensacionalismo em nossos dias. De tão utilizado, tornou-se uma categoria flácida, sem fronteiras e sem vigor. Revela características disseminadas na mídia e evidencia constatações hoje consensuais, sem acrescentar aportes analíticos novos. Ficou muito relacionada ao jornalismo que privilegiava a superexposição da violência por intermédio da cobertura policial e da publicação de fotos chocantes, de distorções, de mentiras, e da utilização de uma linguagem composta por gírias e palavrões.

Os jornais sensacionalistas são historicamente recorrentes, e o sensacionalismo manifesta-se em vários graus. Trata-se de um equívoco tratar do fenômeno in totum. Rotular um jornal de sensacionalista é afirmar apenas que ele dedica-se a provocar sensações. Assim, como se não bastasse o contexto atual remeter-nos a outros recortes de estudo, os referenciais que, normalmente, subsidiam tanto os comentários do senso comum quanto alguns estudos acadêmicos baseados na idéia do sensacionalismo precisam ser revistos.

Muitas vezes, ao taxarmos um jornal de sensacionalista, revelamos, também, uma noção purista e equivocada da atividade. A concepção da notícia como espelho dos fatos faz com que os jornais populares sejam considerados tão somente distorção e subentende que só é desejável uma notícia despida de emoção e narração. Muitas críticas ao exagero e às distorções da imprensa popular, pertinentes do ponto de vista ético, caem no outro extremo de 
imaginar possível uma notícia límpida que faça os fatos transparecerem tal como aconteceram.

Também consideramos que a dicotomia "cultura superior e inferior", que, muitas vezes, envolve os debates sobre o sensacionalismo, é problemática e deve ser substituída por um aparato teórico que tome a cultura como um espectro e responda sobre suas relações com a mídia. Considerar a cultura um espectro não significa ignorar a apropriação desigual do capital cultural e sequer desconsiderar o poder da mídia. As contradições de classe precisam ser somadas à pluralidade de Matrizes Culturais e a análise deve incorporar o âmbito da cultura em que o poder, a dominação e a política são mediados. Os jornais populares moldam seu discurso informativo de acordo com apropriações de características culturais de seus leitores.

Partimos da noção que os interesses econômicos e ideológicos que cercam o segmento popular da grande imprensa dizem respeito a uma das faces do fenômeno. Precisamos reconhecer que o jornal não é uma mercadoria qualquer e, embora possa ser funcional ao sistema, não se limita ao controle político e psicológico. Como lembra Bourdieu, os bens simbólicos têm uma dupla face e são ao mesmo tempo mercadorias e significações (1987, p. 102).

Vivemos num momento em que a maioria dos jornais impressos populares contorna o estilo "sangue e polícia", e, quando utiliza recursos sensacionalistas, aplica-os de outras maneiras, nos fait divers, no relato da vida dos famosos e dos injustiçado, na prestação de serviços, no entretenimento e na criação de espaços do tipo "o povo fala", o que requer novos horizontes de pesquisa.

O jornal Diário Gaúcho (DG) é o nosso objeto empírico. Cristaliza uma série de características que nos levam a problematizar o segmento popular da grande imprensa e suas abordagens mais corriqueiras. O jornal é editado pela Rede Brasil Sul de Comunicações e foi destinado inicialmente à 
Grande Porto Alegre. Sua escolha justifica-se por se tratar de mídia autodenominada popular, cujas especificidades são inéditas no jornalismo impresso do Rio Grande do Sul, e por alcançar mais de um milhão de leitores (jornal mais lido da região). A publicação não tem como elemento central o sensacionalismo policial e integra a tendência de expor cada vez mais pessoas anônimas, especificidade que pretendemos pesquisar.

O jornal surgiu destinado a um público que não costumava ler jornal, a um "lumpezinato da informação", conforme as palavras do editor-chefe do DG em 2001, Cyro Silveira Martins Filho: "é barato, útil, fácil de ler, emocionante, sem ser apelativo, e aborda o cotidiano desse público”. Trata-se de um jornal "no qual pessoas que só seriam notícia em situação de vítimas ou de humilhação são protagonistas de histórias edificantes”, como afirmou o jornalista em 2003 (MARTINS FILHO, 2003, on-line).

Grande parte das notícias do DG é formada por histórias humanas e dramas cotidianos. As pessoas do povo são elevadas à categoria de fonte principal. Há seções dedicadas a publicar as fotos do leitor e de suas festas e comemorações. O leitor é convocado intensivamente a participar do jornal com seus poemas, fotos, reclamações, sonhos e dúvidas. Muitas matérias do jornal são redigidas na forma de side stories. Os populares são freqüentemente ouvidos, a partir da inversão das fontes tradicionais no jornalismo.

Às fontes oficiais fica reservado um papel secundário, pois são acionadas apenas para responder às inquietações dos leitores. As fontes oficiais, citadas secundariamente, nunca aparecem nas fotos e nas legendas. No DG, a necessidade se torna virtude. Aliás, o jornal é o interlocutor que viabiliza a solução de problemas e faz a ponte entre os leitores e as autoridades. As marcas que remetem o texto da notícia ao real são os trechos dos depoimentos das fontes populares. O jornal estabelece um tipo de relação 
social com o leitor popular em que sua fala é digna de crédito, mas este Lugar de Fala só funciona neste mercado.

A construção de um lugar cativo para pessoas anônimas na imprensa é propiciada pelas questões que envolvem a sobrevivência dos jornais. Atualmente, os jornais obrigam-se a satisfazer cada vez mais o público e os anunciantes e, portanto, a se movimentarem cada vez mais em direção ao leitor.

Fortemente subordinado aos esquemas empresariais, o segmento autodenominado popular precisa ser visto em suas múltiplas faces marcadas pelos interesses econômicos e ideológicos, mas também pelas suas necessárias conexões com o mundo popular.

É possível localizar as técnicas de visibilidade do leitor popular tanto nos primórdios do jornalismo sensacionalista americano, quanto nos folhetins originados na imprensa européia. Aliás, muitas formas de visibilidade do popular na mídia podem ser vinculadas a características do gênero melodramático, adotado pelo folhetim francês, e, posteriormente, pelo cinema e pela televisão latino-americanos.

$\mathrm{Na}$ exacerbação da presença do leitor como referente, fonte, autor ou universo cultural, o DG constitui-se num suporte que se utiliza do prestígio do dispositivo jornal para construir sua popularidade de maneira diversa da forma jornalística predominante na imprensa de referência. O jornal interpela a sua temática, a estética e o estilo de um universo cultural popular e a forte presença do discurso de um leitor (que tem nome, endereço e rosto) é decorrência previsível desse processo.

Nosso problema de pesquisa constituiu-se, portanto, em tecer uma rede explicativa para a presença da fala dos populares no DG como elemento chave de conquista de um determinado mercado e construir um ambiente teórico que mostre a lógica da visibilidade do leitor e avalie os impactos dessa presença para o jornalismo. 


\section{Novos aportes para analisar a imprensa}

O conceito de Lugares de Fala é elaborado na tentativa de abordar questões que a noção de sensacionalismo não responde, pois por intermédio dela, normalmente, a imprensa popular é analisada do ponto de vista dos valores que regem a imprensa de referência e o que não corresponde a eles costuma ser rotulado de estratégia mercadológica. No lugar do sensacionalismo, rótulo que nos indica a intensidade de sensações geradas por estratégias como invenções, exageros, distorções e omissões, o Lugar de Fala busca explicar por que a imprensa dirigida a esse público opera com Modos de Endereçamento distintos dos usados na imprensa de referência e constrói sua credibilidade de outras maneiras.

Os Lugares de Fala, no nosso recorte, são as representações das posições sociais e da posse de capital simbólico do jornal e os leitores geradoras de Modos de Endereçamento específicos.

Do nosso ponto de vista, o lugar de onde fala o segmento popular da grande imprensa é diferente do lugar do segmento de referência. A imprensa popular, ao dirigir-se a um outro tipo de leitor, abre Lugares de Fala diferenciados para si, suas fontes e seus leitores e representa em suas páginas posições sociais e capitais simbólicos de maneira diferente. A concepção de Bourdieu de que é toda a personalidade social que está presente na fala do locutor nos é central, ou seja, a razão de ser de um discurso não reside só na competência lingüística do locutor, mas no lugar social a partir do qual o discurso é proferido, nas propriedades pertinentes de uma posição (BOURDIEU, 1994b, p. 167-173), pois toda a estrutura social integra a interação e o discurso.

Um conceito que passou a integrar nossa formulação sobre os Lugares de Fala é o de Modos de Endereçamento, e trata-se da necessidade que a imprensa tem de se conectar com o mundo do leitor e de estabelecer uma relação com ele. Assim, partimos das idéias da autora norte-americana 
Elisabeth Ellsworth (2001) para trabalhar este conceito. Embora os Modos de Endereçamento possam se constituir numa rede complexa de características, vamos destacar aqui a ênfase na interpelação e visibilidade do leitor, pois o DG posiciona o leitor que integra sua fala. Associada a esse conceito, surge a noção da visão antecipada do campo da recepção e a definição de Matrizes Culturais, para mostrar que no processo de a imprensa se fazer popular, ela adota formas culturais consagradas historicamente como populares, que trabalham com uma determinada visão sobre quem são as camadas populares, o que gostam, como vivem e o que consomem. Para trabalhar com as Matrizes Culturais, trazemos os aportes de Raymond Williams (1980) e de Jesus Martín-Barbero (1997). Oswaldo Sunkel (1985) é o autor que orienta o link das Matrizes Culturais e suas representações do popular com a imprensa.

A atividade jornalística tradicional baseia-se em valores de uma Matriz racional-iluminista, mas seu viés popular a transporta para um universo em que dominam elementos de uma Matriz dramática, afinados com as estratégias mercadológicas.

O segmento da imprensa de referência desenvolve-se a partir das noções liberais e iluministas e mesmo que seja inserido na lógica empresarial, define-se como seguidor de princípios ligados à divulgação dos fatos de interesse público. Já o segmento popular está dirigido à necessidade de formação de um público leitor e à ampliação desse mercado e assume a ênfase no entretenimento e na prestação de serviços. Nesses jornais, os temas não são necessariamente o que é importante publicamente, mas sim o que satisfaz o público. A imprensa passa a adotar como estratégia a abordagem de temáticas ligadas ao privado, a um estilo de vida e a um gosto popular.

Por intermédio da análise das posições sociais e da posse de capital simbólico do segmento popular da grande imprensa e do seu leitor-alvo, é possível compreender como os valores jornalísticos tradicionais movimentamse em relação ao mercado para o qual essa imprensa fala. Ao refletirmos sobre 
o conceito prévio que o jornal e os leitores têm de si e do outro, entenderemos a imagem que o jornal têm do leitor popular e os Modos de Endereçamento decorrentes dela, ou seja, como o leitor é interpelado e representado no jornal e por que o leitor tem visibilidade nessa imprensa.

O conceito de Lugar de Fala parte da noção de que os jornais se transfiguram para falar a diferentes leitores por motivos tanto mercadológicos como comunicacionais. Os jornais de referência e os ligados ao segmento popular falam de lugares diferentes, concedem espaços variáveis às vozes oficiais e populares em suas páginas e seus discursos são aceitos em lugares diversos. Com o conceito de Lugar de Fala, demonstramos a importância de o jornalismo ser pensado e analisado em consonância com o mercado simbólico para o qual é produzido, o que não significa aceitar sua subordinação ao mercado, mas sim compreender sua conexão com o mundo popular.

O aporte que propomos reconhece as implicações das posições sociais e simbólicas do jornal e do leitor e incorpora a noção de mercado de leitores, a partir da idéia de que para explicar o discurso, é preciso conhecer as condições de constituição do grupo no qual ele funciona (BOURDIEU, 1994, p. 163). Por isso, consideramos importante analisar a imprensa a partir da preexistência de uma topografia social sobre o jornal, suas fontes e seus leitores (MAINGUENEAU, 1989) e da imagem que esses jornais têm do leitor popular, o que leva ao extravasamento da lógica jornalística e a uma reapropriação de Modos de Endereçamento populares.

O conceito de Lugares de Fala é um instrumento teórico-metodológico que cria um ambiente explicativo (QUADRO 1) para evidenciar que os jornais populares ou de referência falam de lugares diferentes e concedem espaços diversos às falas das fontes e dos leitores, mesmo que sejam editados pela mesma empresa. Assim, cada publicação torna visíveis determinados atores e representa o popular de maneira diversa. 


\section{Quadro 1 - Arquitetura teórico-metodológica}

\begin{tabular}{|c|}
\hline $\begin{array}{c}\text { Busca de novos aportes para compreender o segmento } \\
\text { popular da grande imprensa }\end{array}$ \\
\hline \multicolumn{2}{|c|}{ Visibilidade dos setores populares } \\
\hline $\begin{array}{c}\text { Lugares de Fala na imprensa de referência (habitus jornalístico, lógica autônoma) } \\
\text { Lugares de Fala na Imprensa popular (lógica heterônoma) }\end{array}$ \\
\hline
\end{tabular}

Lugares de Fala do leitor no campo jornalístico

Lugar $=$ posição determinada, espaço ocupado

Fala $=$ discurso proveniente de um lugar

Posição social

$=$ Posição nos diferentes campos

$=$ Posse de capitais econômico, social e cultural (Bourdieu)
Capital simbólico

$=$ Efeitos simbólicos da posse ou destituição dos capitais econômico, cultural e social (Bourdieu)
Visão prévia /Antecipação da imagem do leitor = Condições de recepção antecipadas fazem parte das condições de produção (Bourdieu)

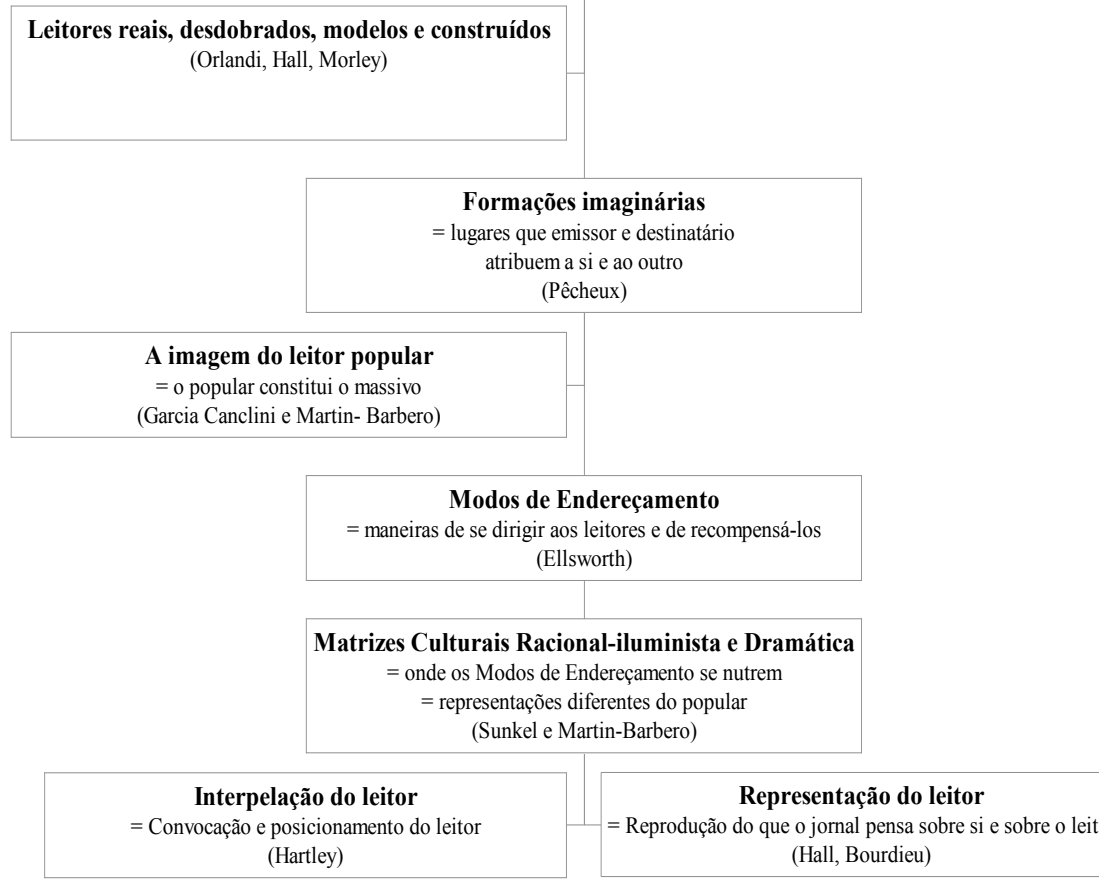


Optamos por abordar o segmento popular da grande imprensa sob o conceito de Lugares de Fala para registrar a importância de estudá-lo no lugar em que ele faz sentido. Não consideramos o jornalismo um discurso único e totalmente autônomo, mas evidenciamos seus aspectos plurais em sua constitutiva tensão com a lógica do mercado e suas relações com vários Modos de Endereçamento.

Se o jornal fala de lugar posicionado socialmente e detentor de um poder simbólico, quando comunicar-se com um público popular, pode optar por falar diferentemente do que se estivesse dirigindo-se a um público formador de opinião. As condições sociais de aceitação do discurso são essenciais para o ato de comunicação, ou seja, as condições de recepção antecipadas fazem parte das condições de produção do discurso.

Quem fala, além de enunciar uma sentença, está envolvido em situações nas quais seu discurso possui um valor. Existe um mercado de sentidos no qual as falas desfrutam de valores diferenciados. A fala, para ser levada em consideração e ser escutada, deve ter legitimidade. Os Lugares de Fala relacionam-se intensamente com as condições de existência de um discurso que são dadas pela resposta às perguntas: Quem pode falar o quê? Para quem? Em que lugar?. (PINTO, 1989, p. 39).

Nessa perspectiva, os jornais constroem representações de si mesmos e de seus públicos por intermédio das posições sociais e dos capitais simbólicos em jogo e da visão prévia que eles têm dos seus leitores.

Ao desmembrarmos o conceito de Lugares de Fala, podemos dizer que a idéia de Lugar nos é bastante significativa, é um espaço ocupado, um ponto de vista relacional, uma posição determinada num conjunto ou um ambiente. A fala é o que exprimimos com a palavra e está associada a uma situação concreta, trata-se do discurso proveniente de um lugar.

A posição social dos agentes pode ser definida pela posição que jornais e leitores ocupam nos diferentes campos, pela distância que os separa 
e pelo volume e estrutura de seus capitais, a partir das características da empresa que edita o jornal e do leitor a quem o jornal se dirige.

Os capitais simbólicos de que jornal e leitor estão investidos são compreendidos como energias baseadas em relações de sentido, reconhecidas socialmente, fundadas sobre a necessidade dos homens de justificarem sua existência social. O capital simbólico não é um tipo de capital como os demais, mas relaciona-se com os efeitos simbólicos dos demais capitais. A imprensa dispõe, além de capitais econômicos, culturais e sociais, de um capital simbólico relevante e sua posição implica uma propensão a falar determinadas coisas de determinadas maneiras. Já o capital simbólico do leitor levado em consideração no campo jornalístico varia de acordo com cada tipo de publicação.

A representação é entendida como a projeção ou a reprodução do que o jornal pensa sobre si mesmo e sobre o leitor. A representação dos agentes sociais integra também sua constituição. A representação parte de um conceito prévio que o jornal tem do leitor, por isso, o jornal adota Modos de Endereçamento, ou seja, bases a partir das quais o jornal interpela e posiciona o leitor. O Modo de Endereçamento refere-se à necessidade que a imprensa tem de se conectar com o mundo do leitor e de estabelecer uma relação com ele. Trazendo para o campo jornalístico, a pergunta central é: Quem esse jornal pensa que você é? Que relação particular o leitor tem com a história contada?. Como o jornal constrói um caminho até o seu leitor? A quem o jornal é endereçado?, Quem esse jornal deseja que o leitor seja?. Ou seja, voluntariamente ou não, os jornais adotam Modos de Endereçamento, que posicionam o leitor popular em lugares diversos do leitor de classe média ou do leitor formador de opinião.

Por antecipação, o jornal projeta um leitor e estabelece suas estratégias com base nele. Por sua vez, o leitor também projeta um jornal e imagina o que a publicação deve dizer e como deve dizer. Tanto o emissor quanto o 
destinatário atribuem lugares a si mesmo e um ao outro e constroem imagens de seu próprio lugar e do lugar do outro. Ou seja, o emissor antecipa as representações do receptor e com a antevisão do imaginário do outro, funda estratégias de discurso. Trata-se de uma antecipação das relações de sentido não totalmente calculada ou planejada, mas seguidora da lógica da experiência, do que “dá certo”, e no caso da imprensa em questão, da lógica do mercado.

É evidente, entretanto, que um jornal pode adotar uma multiplicidade de formas de endereçamento simultâneas, e o leitor também está envolvido em muitas delas em suas experiências cotidianas. Além disso, os leitores podem ler os jornais a partir de outros lugares e responderem de formas diferentes daquelas esperadas. Dessa forma, não há uma coincidência total entre endereço e resposta, mas sim um espaço social formado por uma conjuntura histórica de poder e diferenças sociais e culturais, como afirma Ellsworth (2001, p. 47). Com base na autora (2001, p. 25), podemos afirmar que embora o público não possa ser simplesmente posicionado por um determinado Modo de Endereçamento, os jornais oferecem sedutores estímulos e recompensas para que se assumam aquelas posições de gênero, status social, raça, nacionalidade, atitude, gosto, estilo às quais um determinado produto cultural se endereça.

Se os jornais populares falam de um outro lugar para dirigirem-se ao povo, gerindo de formas diversas suas posições sociais e capitais simbólicos, nesse lugar o povo e seu universo cultural têm ampla visibilidade. O popular, normalmente interditado na imprensa de referência, ganha espaço embora seja mantido numa posição social e simbólica excludente.

As Matrizes Culturais tornadas populares ao longo da história têm subsidiado a imprensa na comunicação com esses setores, por intermédio da tematização dos dramas de reconhecimento; da mediação entre os tempos do capital e da cotidianidade, do entendimento familiar da realidade; da 
confluência público e privado; do desenvolvimento de solidariedades baseadas no local, no parentesco, na vizinhança; da noção de que política só interessa se afeta a vida diária; da ligação entre problemas sociais e dramas pessoais; e a apresentação de personagens "em carne e osso" e assim por diante.

Decorrentes dessa Matriz popular, a incorporação da fala das camadas populares é um dos caminhos amplamente utilizado por essa imprensa. A ancoragem, efeito de atar o discurso a pessoas que o leitor reconhece como existentes, é uma das estratégias para chamar a atenção do leitor popular.

As falas num jornal estão ligadas à complexa rede de interesses que existem na atividade jornalística. Quem fala num jornal, fala a partir de relações objetivas de dominação, subordinação, complementaridade ou antagonismo, ou seja, fala a partir de posições sociais diferentes, que detêm ou não os diversos capitais. Ao campo jornalístico corresponde um mercado simbólico de igual vigor ao de bens materiais, em que os agentes não competem em igualdade de condições. E o poder em jogo é o simbólico, que determina quem tem acesso à visibilidade ou não. O campo jornalístico é regido por determinadas regras que moldam o que é legítimo ser falado e ocorrem muitas disputas no interior do campo em função da variação de posição dos agentes na aceitação, ou não, das demandas mercadológicas. As empresas jornalísticas e os agentes sociais que falam no jornal negociam, entram em confronto, e estabelecem alianças cotidianamente para impor seus modos de percepção, classificação e intervenção na sociedade, ou seja, ambicionam o poder simbólico, o poder de construir a realidade e definir o mundo social.

O conceito de Lugares de Fala é pertinente ao estudo dos jornais autointitulados populares porque registra a importância de estudar a fala no seu lugar. Se o jornalismo de referência fala do lugar de "leitor do mundo", o segmento popular fala do lugar "do mundo do leitor". Assim, o fato de ser dirigido a populares é constitutivo do que os jornais desse segmento dizem. 
O recurso dos Lugares de Fala traz aportes importantes por considerar a movimentação da empresa jornalística em relação a seu público alvo. $\mathrm{O}$ segmento popular da grande imprensa prevê condições de recepção diversas das dos jornais de referência. Os agentes sociais (jornal, fontes e leitores) envolvidos estão em outras posições das verificadas nos jornais tradicionais e embora o lugar social da empresa que mantém o jornal possa ser o mesmo lugar de edição de um jornal de referência.

A imprensa de referência representa-se como quem explica o mundo a um cidadão interessado em compreendê-lo e os lugares disponíveis para as falas do leitor e das fontes relacionam-se ao volume de capital social, econômico e cultural dos agentes. Nos jornais populares, a estratégia muda. A expropriação econômica e cultural do leitor torna-se capital simbólico (a necessidade como virtude) e o jornal fala do mundo das horizontalidades porque os fatos públicos supostamente não interessam aos seus leitores.

\section{De onde fala o leitor}

O DG construiu aspectos peculiares que lhe reforçam a eficácia simbólica a priori estabelecida: atribui a si a função de dar voz aos setores populares, de distribuir o poder de falar nas camadas populares. Como no mundo simbólico nada assume existência antes de ser posto em circulação, parte da assimetria no poder discursivo está na capacidade de fazer circular e tornar os discursos públicos (ARAÚJO, 2003). O jornal distribui o poder de fala ao leitor popular e ele fala de um lugar subalterno, em que, por exemplo, o Estado é ausente (onde falta segurança, educação, assistência à saúde).

Por mais que o leitor fale e transpareça que o jornal dá ao leitor um status de falante, trata-se de uma relação de poder em que a fala é concedida, regulada e editada. A fala popular é uma estratégia e, sobretudo, uma concessão, afinal, na maioria dos jornais há a sua interdição.

O jornal tem uma posição institucional que autoriza o leitor a falar e isso lhe dá legitimidade. Os leitores para quem o jornal se destina e a quem o 
jornal abre suas páginas têm posições desprivilegiadas no espaço social. $\mathrm{Na}$ sua maioria, são destituídos de capital cultural (escolaridade, educação familiar, facilidade de expressão, posse de títulos acadêmicos) e de capital econômico (bens e meios de produção), no sentido que lhes atribui Bourdieu.

Os leitores escolhidos para serem os interlocutores do jornal são pessoas que ocupam posições hierárquicas distanciadas dos poderes instituídos. O jornal privilegia o leitor popular marginalizado e carente de políticas públicas. Muitas vezes, a força do leitor é inversamente proporcional a seu capital econômico, político e cultural (PINTO, 1993), ou seja, quanto mais desprovido de qualquer um destes capitais, mais consegue fazer crer que necessita

Podemos afirmar que, para fins analíticos, que a imprensa dita "de referência" trabalha nos marcos de uma matriz racional iluminista. A Matriz racional-iluminista baseia-se numa linguagem abstrata, interpela o leitor como sujeito político, utiliza-se de uma linguagem rica em conceitos e privilegia assuntos de interesse público e o entendimento histórico-social da realidade. Já o DG faz um jornalismo baseado prioritariamente numa matriz dramática, interpela o leitor como consumidor caracterizada por uma linguagem concreta, baseada em imagens e pobre e conceitos, que prioriza os conflitos interpessoais e o entendimento familiar da realidade.

No DG, o leitor tem visibilidade, mas é representado como alguém sem interlocução com os poderes instituídos, necessitado de prestação de serviço e de assistência social e potencial beneficiário das ações da RBS, consumidor das ações auto-referentes da mídia que envolvem promoções, brindes e entretenimento, fascinado com a visibilidade de seu mundo privado e de seus gostos (gosto popular de contar histórias, interesse pelos dramas do reconhecimento, visão encantada do mundo), desinteressado na explicação de fatos de interesse público, despolitizado e, na maioria das vezes, desligado de movimentos sociais. O jornal posiciona-se como interlocutor junto aos 
poderes instituídos, prestador de serviço e promotor do assistencialismo, integrante de um sistema midiático auto-referente e mídia de amplo acesso popular que fala do ponto de vista do leitor e dá a ele o status de fonte. O DG posiciona-se como um veículo que ilustra o mundo popular, sem a pretensão de explicá-lo, a partir da singularização dos fatos, da dramatização e da adoção de características populares. Considera que a política só é interessante quando afeta a vida diária, aborda situações de exclusão social, mas aponta para soluções individuais e locais e veicula um entendimento familiar da realidade. O público e privado confluem, e há tênue divisão entre informação e entretenimento.

No DG convivem diversas Matrizes culturais em conflito, mas sua peculiaridade está em utilizar-se de elementos da Matriz dramática, com raízes no melodrama e no folhetim. O jornal interpela o popular em sua posição de impotência social e seu restrito entendimento familiar da realidade. Assim como o melodrama, o jornal é escrito para os que têm dificuldades na leitura e são seduzidos pelas imagens, pela retórica do excesso e pelo forte sabor emocional.

O DG herdou do folhetim a interatividade, a cumplicidade com o público e o diálogo com a realidade dos leitores. Das experiências folhetinescas das radionovelas e telenovelas, vem a incorporação do realismo e a viabilização da cotidianização da narrativa.

Reafirmamos a irredutibilidade do segmento popular da grande imprensa ao estatuto de simples mercadoria e o equívoco de considerarmos seu consumo como conseqüência de uma aquisição irracional típica de um segmento de público destituído de cultura.

Ao conceder lugar para a fala dos populares, o DG inova porque no mercado simbólico do campo jornalístico, a manifestação popular tem uma tímida história de inclusão nos jornais impressos, onde os lugares disponíveis para as falas relacionam-se ao volume de capital social, econômico e cultural 
dos agentes. Ao ceder Lugares a esse leitor no jornal, o DG populariza-se a ponto de, por vezes, descaracterizar-se como dispositivo jornalístico. O jornalismo desamarra-se do lugar tradicional de fala em função da visão prévia de seus leitores e assume novos papéis.

O DG cria um modo próprio de lidar com os conceitos de verdade, realidade e credibilidade. O "fazer saber" relaciona-se com outros procedimentos de autenticação e de descrição e o "fazer crer" ocorre a partir de contratos diferentes com o leitor. O efeito de real baseia-se não só no que é realidade, mas também no que é crença, desejo, esperança, sonho e fruição. $O$ jornal abdica de ser um leitor do mundo para abordar o mundo do leitor. $\mathrm{O}$ "fazer sentir" passa a ser uma das atribuições do jornal, mas não somente no sentido de produzir sensações a qualquer custo, mas com a intenção de seduzir o leitor a partir do estímulo da noção de pertencimento social.

No DG, o leitor é desdobrado, exercita sua multiplicidade de identidades, e, se muitas "cabem" nas seções analisadas (o leitor que opina, o leitor necessitado, o leitor indignado, o leitor poeta, o leitor fotógrafo, etc), outras tantas são interditadas (o leitor interessado nos acontecimentos públicos, o leitor eleitor, o leitor militante de movimentos sociais, o leitor que aposta na sua participação na esfera política).

No caso do segmento popular, a fala do leitor, aparentemente democrática e dotada de características qualificadoras, num exame mais apurado pode revelar-se uma mise-en-scène ainda mais complexa na qual o jornal utiliza-se do leitor popular para falar de si mesmo e de suas pretensões para o mundo e seu público.

As pessoas do povo que falam no DG, embora não passivas, não estão em igualdade de condições com os jornalistas e suas fontes tradicionais. Quando publica a fala do leitor, o DG compensa simbolicamente o que a sociedade não oferece aos setores populares como interlocução com o poder e visibilidade e valorização da vida cotidiana, mas segue impondo suas 
definições de mundo social. Tendo em vista que os leitores ocupam diferentes posições, mas a maioria delas é subalterna e revela sua espoliação social, é de se perguntar se é possível um jornalismo destinado às classes populares, ligado ao seu universo cultural, que não as destitua do papel de sujeitos de sua própria história. Afinal, a imprensa tem o papel de mostrar o lugar que cada um ocupa ou pode ocupar no mundo público.

O jornalismo, para popularizar-se, não poderá ignorar o "mundo da vida" e haverá de fazer uma ponte entre sua posição de leitor do mundo e o mundo do leitor. Para tematizar o popular urbano na imprensa, cabe ao jornalismo impresso reconhecer melhor os seus avessos (o que não o constitui por excelência, mas convive com ele), como as necessidades do leitor relacionadas ao entretenimento, à busca da qualidade de vida, às temáticas e aos modos de narrar populares. O jornalismo popular só tem viabilidade se responder a demandas da população e se estiver inserido culturalmente junto ao segmento de leitores a quem se dirige. Para tal, é imprescindível que os jornalistas conheçam previamente seu leitor e estabeleçam Modos de Endereçamento específicos em cada caso.

As Matrizes Culturais tornadas populares ao longo da história têm subsidiado a imprensa na comunicação com esses setores, por intermédio da tematização dos dramas de reconhecimento; da mediação entre os tempos do capital e da cotidianidade, do entendimento familiar da realidade; da confluência público e privado; do desenvolvimento de solidariedades baseadas no local, no parentesco, na vizinhança; da noção de que política só interessa se afeta a vida diária; da ligação entre problemas sociais e dramas pessoais; e a apresentação de personagens "em carne e osso" e assim por diante. Mas é necessário transcendê-las e utilizá-las como catapulta para tornar a narrativa mais relevante à vida do leitor. Se a fala dos populares precisa ganhar espaço nos jornais como um todo e se a força do testemunho popular é chave, o 
habitus jornalístico deve circunscrevê-las à noção do jornalismo como construtor da realidade pública.

A fala do leitor é uma das alternativas para o sucesso do jornalismo destinado aos setores populares, mas pode assumir diferentes configurações. À imprensa é viável utilizar-se de sua força simbólica para representar o leitor das classes menos favorecidas em sua multidimensionalidade. Novos Lugares de Fala podem ser destinados aos setores populares em que essa fala revele vários pontos-de-vista para ver, relatar e construir a realidade, e a partir deles, sejam explicitadas relações sociais que tornem o conhecimento sobre os acontecimentos públicos mais interessantes e próximos de cada cidadão.

O jornalismo destinado aos setores populares, para ser de qualidade, não tem sua definição tão somente na concessão da palavra ao povo, embora se trate de um procedimento de fato relevante, mas sim por conseguir dar espaço à fala popular sem abdicar de seu papel de auxiliar a construir a realidade publicamente relevante.

Mas seria muita soberba desconsiderarmos o papel do DG entre os setores populares. Ao jornalismo não cabe dar voz somente aos que afirmam sua capacidade discursiva, mas também contribuir com a inclusão dos que não se organizam para ter sua fala escutada. Afinal, por mais distantes que estejam as empresas jornalísticas dos leitores das camadas populares, tacitamente todos concordam com a validade da luta por visibilidade. Por mais que a imprensa exerça uma violência simbólica, há a transformação das relações de dominação e de submissão em relações afetivas e se os jornais obtêm lucros materiais e simbólicos com essa medida, ao leitor também cabe um determinado lucro simbólico nessa luta por classificação.

O DG recupera a força da palavra falada, amplifica a fala dos setores populares e coloca o leitor popular, normalmente situado na periferia do direito à fala, no centro do jornal. A miséria, o desemprego, a inoperância do Poder Público e o drama do reconhecimento não se constituem simplesmente 
em recursos estilísticos do jornal para abordar o leitor modelo, mas são problemas efetivamente vividos pelos leitores reais. A existência social é devolvida a pessoas que em outros jornais são reduzidas a problemas sociais ou problemas de polícia, mas o jornalismo não se realiza completamente.

A forma como isso acontece importa-nos sobremaneira porque o DG não simplesmente reproduz em suas páginas o lugar social e simbólico em que situa seus leitores. O jornal corrobora diariamente com um modo de estar dos populares na sociedade, com a constatação das contradições sociais por intermédio dos dramas pessoais. A cada edição, o jornal reafirma esses lugares, reconstituindo-os permanentemente. Os leitores reais também, de alguma maneira, optam por falar no jornal, mesmo que essa escolha se dê por contingências sociais e culturais. Mas os Lugares de Fala não se resumem à posição social do leitor ou à posse de capital simbólico ou ainda a visão que tem da imprensa. Embora o leitor não seja um mero executor do que diz o jornal, o DG recompensa quem assume Lugares de Fala em suas páginas, seja por fruição ou necessidade. E o fato de ser dirigido a populares é constitutivo do que o DG diz. Os Lugares de Fala não apenas emanam ou retratam a existência dos leitores reais e de suas posições. A representação do leitor integra sua constituição.

Sobre o fato dos leitores legitimarem seus Lugares de Fala no jornal DG, entendemos como compreensível, pois o consumo das camadas populares indica uma preferência por informações locais e por indiscrições sobre famosos. Afinal, muitas notícias parecem não corresponder em nada com o mundo do leitor. Como afirma o psicanalista Contardo Calligaris (1998), há uma distância da população da tomada de decisões e da ação concreta e a imprensa tem a tarefa democrática de inventar formas que "criem ou mantenham no leitor o sentimento de que o mundo não lhe é alheio".

Cabe ao jornalismo popular de qualidade trabalhar com dispositivos de reconhecimento e dar conta das multiplicidades culturais, sem perder seus 
propósitos de vista. A grande imprensa tem competência para se fazer escutar e para distribuir o direito de falar, mas aos jornalistas cabe identificar a posição social e simbólica dos leitores populares estruturada extrajornal e abrir novos lugares estruturantes de interpelação e representação de forma a considerá-los cidadãos integrantes do mundo público, porém portadores de características sociais e culturais que lhes dão o sentido de pertencimento.

\section{Referências Bibliográficas}

ARAÚJO, Inesita. Mercado simbólico: um modelo de comunicação para políticas públicas. In: CONGRESSO DA SOCIEDADE BRASILEIRA DE ESTUDOS INTERDISCIPLINARES DA COMUNICAÇÃO, 26, 2003. Anais... GT Comunicação para a Cidadania. Belo Horizonte, set. 2003.

BOURDIEU, Pierre. A Economia das Trocas Simbólicas. 2. ed. São Paulo: Perspectiva, 1987.

. Gostos de Classe e Estilos de Vida. In: ORTIZ, Renato (org.). Pierre Bourdieu. São Paulo: Ática, 1994a, p. 82-121. Coleção Grandes Cientistas Sociais, n. 39.

A Economia das Trocas Lingüísticas. In: ORTIZ, Renato (org.). Pierre Bourdieu. São Paulo: Ática, São Paulo, 1994b. p.156-183. Coleção Grandes Cientistas Sociais, n. 39.

A Economia das Trocas Lingüísticas: O que falar quer dizer. 2. ed. São Paulo: Editora da Universidade de São Paulo, 1998.

ELLSWORTH, Elisabeth. Modo de Endereçamento: uma coisa de cinema; uma coisa de educação também. In: SILVA, Tomaz Tadeu da (org). Nunca Fomos Humanos: nos rastros do sujeito. Belo Horizonte: Autêntica, 2001. p. $07-76$.

MaIngueneau, Dominique. Novas Tendências em Análise do Discurso. Campinas, SP: Editora da Unicamp, 1989. 
MARTIN BARBERO, Jesus. Dos Meios às Mediações: Comunicação, cultura e hegemonia. Rio de Janeiro: Editora da UFRJ, 1997.

MARTINS FILHO, Cyro Silveira. Cyro Silveira Martins Filho: entrevista [jul. 2001]. Entrevistador: Flávio Porcello. Porto Alegre: TV PUC, Programa Argumentos, 2001. [1 VHS].

. Páginas de sangue no Diário Gaúcho. Revista Press. Disponível em: <http://www.revistapress.com.br/press2003/especial26.asp>. Acesso em: 15 abr. 2003.

PEDROSO, Rosa Nívea. A Construção do Discurso de Sedução em um Jornal Sensacionalista. São Paulo: Annablume, 2001.

PINTO, Celi. O clientelismo eletrônico: A eficácia de um programa popular de rádio. Humanas -IFCH/UFRGS, Porto Alegre, v.16, n. 1, p. 117-135, jan./jun., 1993 .

SUNKEL, Guillermo. Razon y Pasion en la Prensa Popular: Un estudio sobre cultura popular, cultura de masas y cultura política. Santiago del Chile: ILET, 1985. 